\title{
The Analysis of Primer Gene of Phosphodiesterase Type 5 (PDE5) on Erectyle Dysfungction
}

\section{Theopilus W. Watuguly¹, Indranila K. Samsuria ${ }^{2}$, Pudji Astuti ${ }^{3}$, Tri Rini Nuringtyas ${ }^{4}$, Nastiti Wijayanti' ${ }^{4}$, Syahran Wael1,4}

\author{
${ }^{1}$ Department of Biology, Pattimura University, Maluku, Indonesia \\ ${ }^{2}$ Department of Clinical Pathology, Diponegoro University, Semarang, Indonesia \\ ${ }^{3}$ Department of Veterinary Medicine, Gadjah Mada University, Yogyakarta, Indonesia \\ ${ }^{4}$ Department of Biology, Gadjah Mada University, Yogyakarta, Indonesia \\ Email: twatuguly@gmail.com
}

How to cite this paper: Watuguly, T.W., Samsuria, I.K., Astuti, P., Nuringtyas, T.R., Wijayanti, N. and Wael, S. (2018) The Analysis of Primer Gene of Phosphodiesterase Type 5 (PDE5) on Erectyle Dysfungction. Open Journal of Applied Sciences, 8, 398-410.

https://doi.org/10.4236/ojapps.2018.89030

Received: July 26, 2018

Accepted: September 25, 2018

Published: September 28, 2018

Copyright $(9) 2018$ by authors and Scientific Research Publishing Inc. This work is licensed under the Creative Commons Attribution International License (CC BY 4.0).

http://creativecommons.org/licenses/by/4.0/

\begin{abstract}
Backround: Erectile dysfunction (ED) is the inability of male reproductive organs within sexual intercourse caused by neurogenic and hormonal disorders. There are some causes of ED such as hypertension, stress, neurological disorders, stroke, diabetes, atherosclerosis, lifestyle, alcohol, smoking, and age-related hormonal decline can cause infertility. The natural treatment of sexual dysfunction through aphrodisiac activity of the plant is to increase sexual hormones, spermatogenesis activity and through PDE5 inhibitors such as sildenafil, verdenafil, and tadalafil which can inhibit the hydrolysis of second messenger cGMP of penis smooth muscle cells. Primer Design for amplification of several PDE5 gene nucleotide sequences obtained from NCBI gen banks and tested directly through explosions at NCBI and also using MEGA 6, primer 3 plus, and fast PCR software. The natural treatment of sexual dysfunction through aphrodisiac activity from plants to increase sexual hormone, spermatogenesis activity and inhibitor PDE5 such as sildenafil, vardenafil, and tadalafil can inhibit hydrolysis second messenger of cells cGMP smooth penis muscles. Method: Primer design stages for several sequences are data supply, multiple sequence alignment, sequence trimming, primer design (fastPCR input), in silico PCR analysis, and primer evaluation (Primer Test, OligoCalc and BLAST). Results: Primer of PDE5 that is choosen is with reverse sequence 5-TGCATTGACCATGTCTCTCGTT-3, forward 5-CGCCGATCTGGGCTGAACTA-3 able to amplify template DNA at temperature $67.2^{\circ} \mathrm{C}, 65.8^{\circ} \mathrm{C}, 63.7^{\circ} \mathrm{C}$, however, the DNA band fragment looks not very clear, while it is more clearly seen at $\mathrm{Tm}$ temperature $61.2^{\circ} \mathrm{C}, 59.1^{\circ} \mathrm{C}$, $57.8^{\circ} \mathrm{C}$ and $57^{\circ} \mathrm{C}$. Conclusion: PDE5 primers can be amplified well at
\end{abstract}


temperature $61.2^{\circ} \mathrm{C}, 59.1^{\circ} \mathrm{C}, 57.8^{\circ} \mathrm{C}$ and $57^{\circ} \mathrm{C}$. PDE5 primer succeeded in amplifying DNA with a product length of $402 \mathrm{bp}$.

\section{Keywords}

Erectile Disfunction, PDE5, Primer, PCR

\section{Introduction}

Phospodiesterase is a group of enzymes that break down substrates such as phosphodiaterases which bind pyrophosphates from nucleotides and nucleotide sugars [1]. PDE5 degrades cyclic AMP (cAMP) and cyclic GMP (cGMP) second messenger molecules [2]. PDE5 has important role in transferring signal transduction because PDE5 regulates nucleotide signals [3]. PDE5 often becomes the target of drugs, because it has the ability to regulate small levels of nucleotides, tissue distribution, substrate specificity and parmocology [4]. PDE5 is mediated by cAMP and cGMP so it is used as a therapy to treat erectile dysfunction, asthma, heart failure, inflammation and depression [5]. PDE5 plays a role in cAMP and cGMP degradation. The role of PDE5 is related to adenylate silage (AC) and guanylate cyclase (GC) in regulation and the duration of the intracellular signaling mechanism [6]. cGMP hydrolyzes PDE5 which is expressed in vascular smooth muscle.

PDE5 is found in the penile tissue of the corpus cavernosum which functions to regulate erectile physiology so that it can be used as a therapy or treatment for sexual dysfunction [1]. Erectile dysfunction can be detected by examining PDE5 gene expression [4]. The success of PDE5 examination depends on the primer being designed [7]. The results of previous studies show that not all primers can detect the presence of PDE5. Chen et al. (2017) carried the research on culture neurons with maturation interference effects using PDE5 primers with sequences forward: CCGATCTGGGCTGAACTAACAA, reverse:

CAGACAAGGAACAGGGAATAGC, there is no increase in neurons in the effects of maturation interference [8]. Whereas PDE5 primers that succeeded in amplifying DNA were carried out by Ryu et al. (2018) with sequence forward: AACTATTACTGTCAACGACTTACAGTTT, reverse:

GCTTGGTCTTGAATGAAGTCA, successfully demonstrated that udenafil suppresses TLR4 mRNA expression in the hypothalamus [9]. Another study conducted by Fiore et al. (2018) with sequence forward:

GGAGGAGAATACTGGCAAGA, reverse: GATGCATGGTAAGACAGGAC; in type 2 diabetic mice administrated sildenafil for 12 weeks could increase adipogenesis and improve adipose tissue [10]. The amplification of PDE5 gene depends not only on the primers determined, but it also depends on other factors such as dNTP, PCR templates, number of cycles, polymerase enzymes, and technical and non-technical effects [11]. 
Repair of erectile dysfunction is done by detecting the PDE5 gene [12], then giving treatment with chemical compounds that believe to act as PDE5 inhibitors [13]. Erectile dysfunction is the inability to achieve or maintain penile erection sufficient to have sexual intercourse with a partner [14]. Erection of the penis is influenced by various factors such as neuroendocrine and vascular mechanisms acting on the penis tissue [15] consisting of a pair of corpus cavernous and corpus spongiosum [16], where in the middle runs the urethra [17]. The results of the Massachusets Male Aging Study (MMAS) survey, in men aged 40 - 70 years get $52 \%$ of respondents suffered from erectile dysfunction (ED) to a certain degree, where the total ED were suffered by $9.6 \%$, mild by $25.2 \%$ and minimal by $17.2 \%$. In Indonesia who come to the clinic of impotence, the result estimated is not much different.

Erectile dysfunction is the inability of the male reproductive organs to have sexual intercourse due to the absence of penis erection [18]. The male reproductive system consists of the hypothalamus, pituitary, and testis [19]. Until now there have been much controversy about the cause of penis inability to erect ment is better and quality of life can be improved [20]. Causes of erectile dysfunction such as hypertension, stress, neurological disorders, stroke, diabetes, atherosclerosis, lifestyle, alcohol, smoking, and age-related hormonal dysfunction can cause infertility [15] [21] [22].

The natural treatment of sexual dysfunction through aphrodisiac activity [23] of the plant is to increase sexual hormones and spermatogenesis activity and through PDE5 inhibitors such as sildenafil, verdenafil, and tadalafil which can inhibit the hydrolysis of second messenger cGMP released into the muscle cells smooth penis [24]. One of the newest and can be taken orally is sildenafil citrate. Originally sildenafil is meant to treat heart disease. Apparently people obtained side effects such as increased erection [23]. The erection process normally depends on the balance process between the contraction phase and the relaxation of the smooth muscle cells of the penis that is influenced by the production of cyclic guanosine monophosphate (cGMP) [13]. Cyclic guanosine monophosphate is not continuously present because it will subsequently be degraded by PDE5 [12].

Phospodiesterase type 5 is often a drug target, as it has the ability to regulate nucleotide cyclic levels, tissue distribution, substrate specificity and parmocology [4]. The PDE inhibitor reduces cGMP-phospodiesterase so as to keep the blood vessels in the penis filled and the erections persist, extending or enhancing the physiological process effects mediated by cAMP and cGMP [24]. Erection begins with sexual stimulation of the parasympathetic nerve releasing No. Nitric Oxide is released when there is sexual stimulation. Nitric Oxide diffuses to the smooth muscle cells of the corpus cavernosum and activates the guanilic cyclase (GC) enzyme then converts the GTP nucleic into cGMP [18]. Cyclic guanosine monophosphate causes smooth muscle cells around the penis to become a relaxation that leads to an increase in blood in the penis tissues [23]. Blood is 
then trapped in the penis resulting in an erection. Erection stops because the enzyme PDE5 hydrolyzes cGMP. Phosphodiasterase type 5 enzymes are in the penis tissue [18]. Erection process due to sexual stimulation can be seen in Figure 1.

Erections are controlled by the corpus cavernosum through No. Nitric oxide (NO) is synthesized by the amino acid arginine and it is the main neurotransmitter responsible for muscle relaxation in the penis tissues [13]. Testosterone also plays a role in modulation of erectile function and is responsible for the regulation of nitrite oxide synthase (NOS) for cGMP formation [4]. Treatment of erectile dysfunction can be done through PDE5 inhibitors that found in plants or foods that contain aphrodisiac compounds. Aphrodisiacs are substances that can increase sexual arousal or libido [25]. Aphrodisiacs are categorized into three groups: 1) substances that increase libido such as sexual desire, sex drive, 2) substances that increase sexual potency such as erectile effectiveness, 3) substances that increase sexual pleasure [22]. The effectiveness of aphrodisiac can improve the stimulation of sexual behavior of the hypothalamus, pituitary, gonad, and rapidly increasing erections. The role of PDE is related to adenylyl cyclase (AC) and guanilic cyclase (GC) in the regulation and duration of the intracellular signaling mechanism [22]. Phospodiasterase type 5 hydrolyzes cGMP expressed the smooth muscle of the penis corpora cavernosum and vascular smooth muscle cells that enable the work of PDE5 inhibitors to regulate erectile dysfunction [4] (Table 1).

Table 1. TaqMan human phospodiasterase gene test.

\begin{tabular}{llll}
\hline Group & Category Description & $\#$ & Human Gene Symbols \\
\hline PDE1 & CaM-dependent PDE & 3 & PDE1A-PDE1C \\
PDE2 & cGMP-stimulated PDE & 1 & PDE2A \\
PDE3 & cGMP-inhibited PDE & 2 & PDE3A, PDE3B \\
PDE4 & cAMP-specific PDE & 4 & PDE4A-PDE4D \\
PDE5 & cGMP-specific PDE & 1 & PDE5A \\
PDE6 & Photoreceptor PDE & 6 & PDE6A-C, PDE6D, PDE6G, PDE6H \\
PDE7 & cAMP-specific PDE & 2 & PDE7A, PDE7B \\
PDE8 & cAMP-specific PDE & 2 & PDE8A, PDE8B \\
PDE9 & cGMP-specific PDE & 1 & PDE9A \\
PDE10 & dual specificity PDE & 1 & PDE10A \\
PDE11 & dual specificity PDE & 1 & PDE11A \\
ENPP & ectonucleotide PPase/PDE & 7 & ENPP1-7 \\
SMase & sphingomyelin PDE, neutral & 2 & SMPD2, SMPD3 \\
ASM & sphingomyelin PDE, acid-like & 3 & SMPD1, SMPDL3A, SMPDL3B \\
GDPD & glycerophosphodiester PDE & 6 & GDPD1-5, MIR16 \\
CNP & 2 '3'-cyclic nucleotide 3' PDE & 1 & CNP \\
Controls & & 5 & 18S, ACTB, B2M, GAPDH, PPIA \\
TOTAL & & 48 & \\
\hline & & & \\
\hline
\end{tabular}




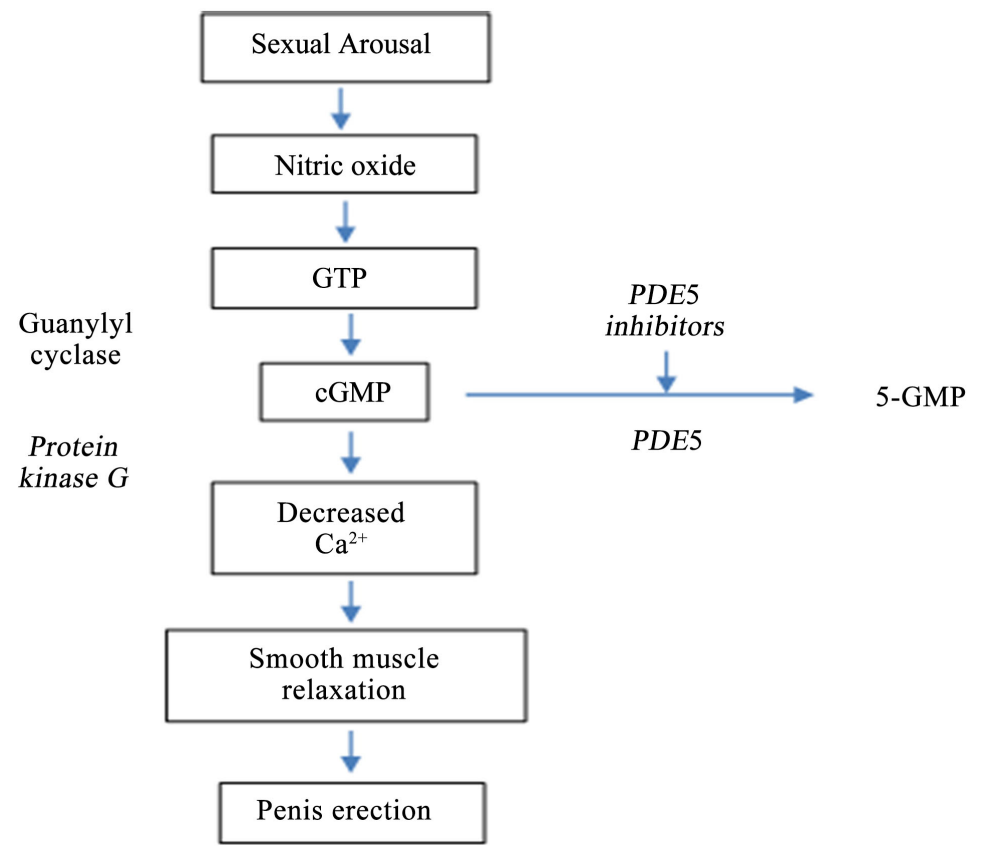

Figure 1. Sexual stimulation that causes erections [3].

\section{Methods}

\subsection{Collecting Primer PDE5}

This study used software to identify the PDE5 gene that used to amplify the DNA template in polymerase chain reaction (PCR). The primer design for amplification of several PDE5 gene nucleotide sequences from FastPCR and genbank software (http://www.ncbi.nlm.nih.gov/) was tested directly on NCBI and used MEGA 6, primer 3 plus, and fastPCR. the primer design results obtained from the software are then filtered according to criteria design stages for multiple sequences are data inventory, multiple sequence alignment, sequence trimming, primer design (Input fastPCR), PCR in silico analysis, and primer evaluation (Primer Test, OligoCalc and BLAST). For Single sequences, it started with Inventory data, primer design (Input fastPCR), PCR analysis in silico, primer evaluation (Primer Test, OligoCalc and BLAST). Primer evaluation consists of Primer Test: Displays the primer character, oligocalc; The primer secondary structure, blast; searches primers in the overall genome (primer specific evaluation). The primer types are as follows; Primer gene specific (forward and reverse primer), oligo dT (16 - 20 primers) PCR mRNA. Primer size 18 - $20 \mathrm{bp}$, Percentage GC contents $40 \%-60 \%$, Tm per primer 55 - 60 centigrade, difference of forward and reverse primer not more than 2 Celsius, 3 ' end each primer there is $\mathrm{G}$ or $\mathrm{C}$ ( 5 last base there is $2 \mathrm{G}, 2 \mathrm{C}$ or $\mathrm{GC}$ ), there is no recurrent base, avoid primer-template mismatch at $3^{\prime}$ end, and avoid secondary structures formed on primers such as hairpin, self-complementary, and primer dimer.

Hairpin;

Self-complementary, and primer-dimer;

From the results of the primary analysis, each design has 10 primers that are 
strong candidates to choose from, but in this study only three primers to strengthen the DNA template that will be tested. The chosen primary is:

From the results of the primer analysis, each design has 10 primers that are strong candidates to be chosen, but in this, there were three primers to amplify template of DNA that would be tested. The selected primersare:

1) Sequence forward: 5-CGCCGATCTGGGCTGAACTA-3 reverse: 5-TGCATTGACCATGTCTCTCGTT-3;

2) Sequence forward: 5-GCCGATCTGGGCTGAACTAAC-3 reverse: 5-GCTCACGGTTCCCTCAGAAT-3;

3) Sequence forward: 5-CTGGGCTGAACTAACAAGCTC-3 reverse: 5-AGAAAGCTCACGGTTCCCTC-3.

\subsection{PCR Procedure}

The purpose of PCR is to make a number of copies of a gene that amplified. 30 40 cycles of PCR reaction cycle that took place in the machine. The PCR stage included denaturation at $94^{\circ} \mathrm{C}$, anneling $54^{\circ} \mathrm{C}$ for primer attachment, extension at $72^{\circ} \mathrm{C}$. PDE5 gene amplification uses RT-PCR. The forward primer initiated the DNA multiplication process while the reverse primer limits the DNA polymerization reaction according to the expected product. The template of DNA obtained from cDNA synthesis would be added to the micro PCR tube according to the $\mathrm{GoTaq}^{\circledast}$ Green master mix kit procedure for $25 \mu$ of reaction volume. Primers completed the template through the anneling process, then the extension process occured from the end of the 5-phosphate to the $3-\mathrm{OH}$ end. The primer synthesized DNA exactly the same as the DNA template and produced the product as expected. Primers that hybridize more than one target area indicated the primer non-specific to the template. Primer used to produce cDNA for PCR assays, as a new origin of DNA synthesis, and as the origin of DNA sequencing.

\section{Results and Discussion}

\subsection{Primer Design}

The primer design for the amplification of several nucleotide sequences of the PDE5 gene from FastPCR software and genbank (http://www.ncbi.nlm.nih.gov/) was tested directly by blast on NCBI or also using MEGA 6, primer 3 plus, and fastPCR. NCBI is a server that contains data base about information [26]. This data base continues to be updated in accordance with the latest discoveries concerning DNA, proteins, RNA compounds and others. There are three data base bases in the world that always exchange information that is genbank owned United States, EMBL (the European Molecular Biology Laboratory), and DDBJ (DNA Data Bank of Japan) [27].

Primer is a single short piece of DNA (oligonucleotide), a commonly used primer length ranging from 18 to 20 bases. Primer is one of the essential ingredients required in polymerase chain reaction (PCR). Primer serves to initiate 
polymerase chain reaction (PCR). It also serves to limit the area to be amplified in the PCR reaction [7]. Without a primer, PCR reactions will not occur even if enzymes and other components are readily available [28]. Ideally the primer has the right nucleotide base sequence in pairs with the base sequence of the target DNA to be amplified, and not attached to other non-targeted parts (mispriming). Besides, it also pays attention to the arrangement of nucleotides, such as \% GC, and the difference between temperature mealting between primer forward and primer reverse which is not too far $2 \mathrm{C}$ differences ideally [7] [28].

\section{1) The Inventory data from GenBank}

The design of PDE5 primers was carried out using the wistar rat nucleotide sequence accessed at NCBI (www.ncbi.nlm.nih.gov) with access code NM_133584.1 GI: 19424279 with nucleotide bases is 3397 bp linear mRNA. The search is done by entering the PDE5 keyword on the NCBI home page by genre search type or nucleotide. Thereafter it obtained two different sequences of PDE5 nucleotides from different animals and humans. The sequence in detail it can be seen in fasta and next the nucleotide sequence copied to the notepad with fasta format, then it can blast through pick primers, and get primer so it will appear a number of desired primers. In addition it also can by using software mega 6.06 through multiple sequence alignment, the sequences that have been successfully loaded will be in alignment, then do trimming sequences which are not used as a template in the primer design. Trimming sequences are performed on upstream and downstream sequences of alignment results. Limited trimming until found. The alignment results are then stored in fasta format for use as the template design primer and PCR in silico.

\section{2) Selection of candidates or primer selection}

Primer that has been obtained then is selected to determine the primers to be used. In general, primer selection depends on the purpose of amplification. Primer selection is expected according to the criteria so that a primer can be declared good.

\section{3) Analysis PCR in silico}

PCR in silico is done using FastPCR software. The sequences are performed by uploading PCR, then running, so the columns in PCR silico result can be seen in the primer attachment area in each sequence, the nucleotide sequence and the position of the attachment area, the percentage of the primer attachment, the melting temperature and the size of the amplicon. The primer attachment area can be seen in the red column of nucleotide sequences showing the primer forward attachment region and the blue-colored nucleotide being the primer reverse attachment region.

\section{4) Checking the primer characters}

The Fast PCR software can check the primary character through the primary test column. Primary nucleotides are inputted in the provided column, then in the oligo analysis column it will display the primary character in full so that it is adjusted whether the primer meets the criteria or not. Checking primary characters can also be done with oligocalc, a tool to test the primary characters 
provided on the page http://biotools.nubic.northwestern.edu.OligoCalc.html.

\subsection{Primer Design Results}

Primer PDE5 design results using FastPCR software obtained primer forward as much as 30 and primer reverses 31 for the first sequence inventory. PCR in silico analysis results obtained 10 primers (Table 2 ).

In the second sequence obtained forward primer 23 and reverse primer 22. Primer design results of genbank software (http://www.ncbi.nlm.nih.gov/) (Table 3).

From the results of the primary analysis, there were 10 primers who became strong candidates to be chosen. But in this study, it was filtered again into three primers used to amplify DNA templates. The selected primary consists of 1) sequence forward: CGCCGATCTGGGCTGAACTA reverse:

TGCATTGACCATGTCTCTCGTT, 2) forward:

GCCGATCTGGGCTGAACTAAC reverse: GCTCACGGTTCCCTCAGAAT, 3) forward: CTGGGCTGAACTAACAAGCTC reverse:

AGAAAGCTCACGGTTCCCTC.

Primer is a component of PCR that determines the accuracy of DNA sequences that want to be amplified. The nucleotide sequence (primer) will be the determinant on which part of the primer will attach (anneal) to the genome [27]. If the nucleotide sequence does not match the gene code we want, it is sure that the result of PCR product is not satisfactory. Therefore, before stepping on the amplification stage with PCR, the use of primer should be ascertained prior to its specificity. The trick is to make the primer design [26].

From the results of successful primer candidates, one is considered to have more criteria as a potential primer pair used on amplification using PCR. Primer selection with consideration compared to the other primer pair 1 which has a small $\mathrm{Tm}$ so that it can anticipate the primer synthesis process. The primer of the design will usually be different with from the synthesis and with a slight temperature difference it will allow a slight difference in the synthesis results. The two primer couples obtained had the same GC content of 55\%. The PDE5 primers above only 1 primer is good to use when compared to other primers (Table 4).

\subsection{PDE5 Assay}

There are 24 different superfamilies of PDE5 genes that clasify into 11 different groups. PDE degrade the molecular second messenger cyclic AMP (cAMP) and cyclic GMP (cGMP) [3]. PDE plays an important role in signal transduction because PDE regulates nucleotide signals. PDE often is the target of drugs, because they have ability to regulate nucleotide nucleotide levels, tissue distribution, substrate specificity and parmocology [29]. PDE5 inhibitors extend or enhance the effects of pyatologic processes mediated by cAMP and cGMP. It also used as therapy for erectile dysfunction, asthma, heart failure, inflammation and depression [3]. 
T. W. Watuguly et al.

Table 2. Primer design results.

\begin{tabular}{|c|c|c|c|c|c|}
\hline Primer ID & Sequence $\left(5^{\prime}-3^{\prime}\right)$ & $\operatorname{Tm}\left({ }^{\circ} \mathrm{C}\right)$ & Primer_Quality (\%) & PCR_Fragment_Size (bp) & Topt $\left({ }^{\circ} \mathrm{C}\right)$ \\
\hline 1F3_1_72-89 & CTGGGCTGAACTAACAAGCTC & 53.0 & 92 & & \\
\hline 1R2_1_316-333 & AGAAAGCTCACGGTTCCCTC & 50.2 & 89 & 263 & 601 \\
\hline 1F3_1_72-89 & TTACCGACTTCAGCGGAT & 53.0 & 92 & & \\
\hline 1R21_1_156-174 & CACTGAGCCGTGTTAAAGC & 55.3 & 87 & 104 & 58 \\
\hline 1F3_1_72-89 & TTACCGACTTCAGCGGAT & 53.0 & 92 & & \\
\hline 1R22_1_137-156 & CTTTGTGGTAGGCTCCGTCT & 57.0 & 87 & 86 & 57 \\
\hline 1F3_1_72-89 & TTACCGACTTCAGCGGAT & 53.0 & 92 & & \\
\hline 1R6_1_293-310 & GTGCTCCATGGCAGTACA & 55.3 & 87 & 240 & 59 \\
\hline 1F3_1_72-89 & TTACCGACTTCAGCGGAT & 53.0 & 92 & & \\
\hline 1R23_1_119-136 & TCTTTCCATCGGCAAAGA & 51.3 & 87 & 66 & 56 \\
\hline 1F3_1_72-89 & GCCGATCTGGGCTGAACTAAC & 53.0 & 92 & & \\
\hline 1R13_1_223-242 & GCTCACGGTTCCCTCAGAAT & 57.7 & 87 & 172 & 602 \\
\hline 1F3_1_72-89 & TTACCGACTTCAGCGGAT & 53.0 & 92 & & \\
\hline 1R7_1_284-303 & ATGGCAGTACAGCCAAGGTC & 57.8 & 87 & 233 & 58 \\
\hline 1F3_1_72-89 & TTACCGACTTCAGCGGAT & 53.0 & 92 & & \\
\hline 1R11_1_247-266 & AATCATGGCTTAAAGCGGCA & 55.3 & 87 & 196 & 58 \\
\hline 1F22_1_256-277 & AAGCCATGATTTGGACCATCGT & 56.9 & 90 & & \\
\hline 1R5_1_295-316 & TTGATGGTGCTCCATGGCAGTA & 58.3 & 88 & 62 & 61 \\
\hline 1F22_1_256-277 & CGCCGATCTGGGCTGAACTA & 56.9 & 90 & & \\
\hline 1R6_1_293-310 & TGCATTGACCATGTCTCTCGTT & 55.3 & 87 & 56 & 402 \\
\hline
\end{tabular}

Table 3. Primer design results.

\begin{tabular}{|c|c|c|c|c|c|}
\hline Primer ID & Sequence $\left(5^{\prime}-3^{\prime}\right)$ & $\operatorname{Tm}\left({ }^{\circ} \mathrm{C}\right)$ & Primer_Quality (\%) & PCR_Fragment_Size (bp) & Topt $\left({ }^{\circ} \mathrm{C}\right)$ \\
\hline 2F7_1_68-87 & CTGGGCTGAACTAACAAGCTC & 59.9 & 90 & & \\
\hline 2R5_1_262-280 & AGAAAGCTCACGGTTCCCTC & 57.3 & 97 & 214 & 601 \\
\hline 2F12_1_209-230 & CTGTGATCTCTCCGCCATTACT & 56.5 & 88 & & \\
\hline 2R5_1_262-280 & AATTCGGCTGCCACGAGTT & 57.3 & 97 & 73 & 61 \\
\hline 2F9_1_179-198 & GGAGTTGTTTCTGGCAATGC & 56.2 & 87 & & \\
\hline 2R5_1_262-280 & AATTCGGCTGCCACGAGTT & 57.3 & 97 & 103 & 61 \\
\hline 2F2_1_4-24 & CGCCATGATTTGGACCATCGT & 58.4 & 85 & & \\
\hline 2R5_1_262-280 & AATTCGGCTGCCACGAGTT & 57.3 & 97 & 278 & 63 \\
\hline 2F14_1_227-247 & TACTAAGCCCTGGCCTATTCA & 54.8 & 85 & & \\
\hline 2R5_1_262-280 & AATTCGGCTGCCACGAGTT & 57.3 & 97 & 55 & 59 \\
\hline 2F17_1_251-268 & CGCCGATCTGGGCTGAACTA & 52.6 & 92 & & \\
\hline 2R4_1_282-299 & TGCATTGACCATGTCTCTCGTT & 52.5 & 88 & 50 & 402 \\
\hline 2F17_1_251-268 & ACGGATAGCAGAACTCGT & 52.6 & 92 & & \\
\hline 2R2_1_330-347 & GGGCCTCAGCGTCTATGA & 57.0 & 86 & 98 & 57 \\
\hline 2F7_1_68-87 & GCCGATCTGGGCTGAACTAAC & 59.9 & 90 & & \\
\hline 2R7_1_248-268 & GCTCACGGTTCCCTCAGAAT & 55.6 & 88 & 202 & 602 \\
\hline 2F1_1_2-21 & GGCGCCATGATTTGGACCAT & 59.1 & 79 & & \\
\hline 2R5_1_262-280 & AATTCGGCTGCCACGAGTT & 57.3 & 97 & 280 & 63 \\
\hline 2F12_1_209-230 & CTGTGATCTCTCCGCCATTACT & 56.5 & 88 & & \\
\hline 2R4_1_282-299 & GATCAGCGGCATGTTCTA & 52.5 & 88 & 92 & 57 \\
\hline
\end{tabular}


Table 4. Primers PDE5 that have been used.

\begin{tabular}{lll}
\hline Name & Sequence & Use \\
\hline PDE-RT & AATTCAGAGGCAGAGAT & RT primer [18] \\
PDE5A-s & TGATCACCGGGACTTTACCT & PDE5A1 specific [18] \\
PDE5B-s & TGCTATGTTGCCCTTTGGAG & PDE5A2 specific [18] [30] \\
rPDE5A3 & AGCCTGGGTGTAGCAGCTT & Rat PDE5A3 specific [30] \\
Reverse & ACCCTCATAGATGGGCACAG & primer (R) wistar control [29] [30] \\
Forward & AGCCATGTACGTAGCCATCC & primer (F) wistar control [29] [30] \\
\hline
\end{tabular}

PDE5 plays a role in cAMP and cGMP degradation. The role of PDE5 is related to adenylate silase (AC) and guanilic cyclase (GC) in the regulation and duration of the intracellular signaling mechanism [6]. cGMP hydrolyzes PDE5 expressed to the smooth muscle of the penis corpus cavernosum and the smooth muscle cells of the pulmonary vessels that enable the work of PDE5 inhibitors to regulate erectile dysfunction [30]. The primar success of PDE5 in amplifying DNA templates can be seen in Figure 2.

Primer PDE5 (A) with sequence reverse 5-TGCATTGACCATGTCTCTCGTT-3, forwad 5-CGCCGATCTGGGCTGAACTA-3 able to amplify template DNA at temperature $67.2^{\circ} \mathrm{C}, 65.8^{\circ} \mathrm{C}, 63.7^{\circ} \mathrm{C}$, however, the DNA band fragment looks not very clear, while it is more clearly seen at $\mathrm{Tm}$ temperature $61.2^{\circ} \mathrm{C}, 59.1^{\circ} \mathrm{C}$, $57.8^{\circ} \mathrm{C}$ and $57^{\circ} \mathrm{C}$. Figure 3, PDE5 primer succeeded in amplifying DNA with a product length of $402 \mathrm{bp}$. Whereas primars (B) and (C) on electrophoresis results with various optimization temperatures show unclear amplification in bands that appear with sequences (B) forward: GCCGATCTGGGCTGAACTAAC reverse: GCTCACGGTTCCCTCAGAAT, and sequences (C) forward: CTGGGCTGAACTAACAAGCTC reverse: AGAAAGCTCACGGTTCCCTC.

Electrophoresis results of primar $\mathrm{A}$, at $68^{\circ} \mathrm{C}$ did not succeed in amplifying the DNA template, while the temperature of $67.2^{\circ} \mathrm{C}, 65.8^{\circ} \mathrm{C}, 63.7^{\circ} \mathrm{C}$, was succeed in amplifying but the band that appeared was not very bright while the temperature of $61.2^{\circ} \mathrm{C}, 59.1^{\circ} \mathrm{C}, 57.8^{\circ} \mathrm{C}, 57^{\circ} \mathrm{C}$ bands was brighter. The brighter band indicates higher DNA concentration than the less bright band. Primar B was at $63.7^{\circ} \mathrm{C}$, $61.2^{\circ} \mathrm{C}, 59.1{ }^{\circ} \mathrm{C}, 57.8^{\circ} \mathrm{C}, 57^{\circ} \mathrm{C}$ bands that appeared not too bright, and primer $\mathrm{C}$ at $68^{\circ} \mathrm{C}$, and $67.2^{\circ} \mathrm{C}$ did not occur DNA amplification, but at temperatures $65.8^{\circ} \mathrm{C}, 63.7^{\circ} \mathrm{C}, 61.2^{\circ} \mathrm{C}, 59.1^{\circ} \mathrm{C}, 57.8^{\circ} \mathrm{C}$, and $57^{\circ} \mathrm{C}$ it was managed to amplify but the band that appeared was not too bright. From the 3 primers of PDE5 tested, there was only one primer that considered to be better at amplifying DNA templates. This shows that primers selection was strongly to determine the success of the DNA template amplification process.

\section{Conclusion}

The success of PDE5 gene amplification is highly dependent on the primer, the results of the primer design selected 3 primers that met the criteria, but there was only 1 primer to electrophoresis results was able to amplify the DNA 


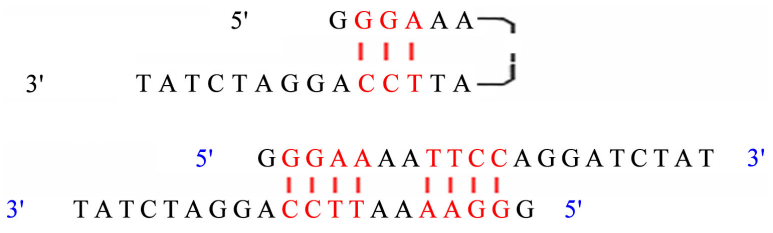

Figure 2. Hairpin and self-complementary and Primer-dimer.
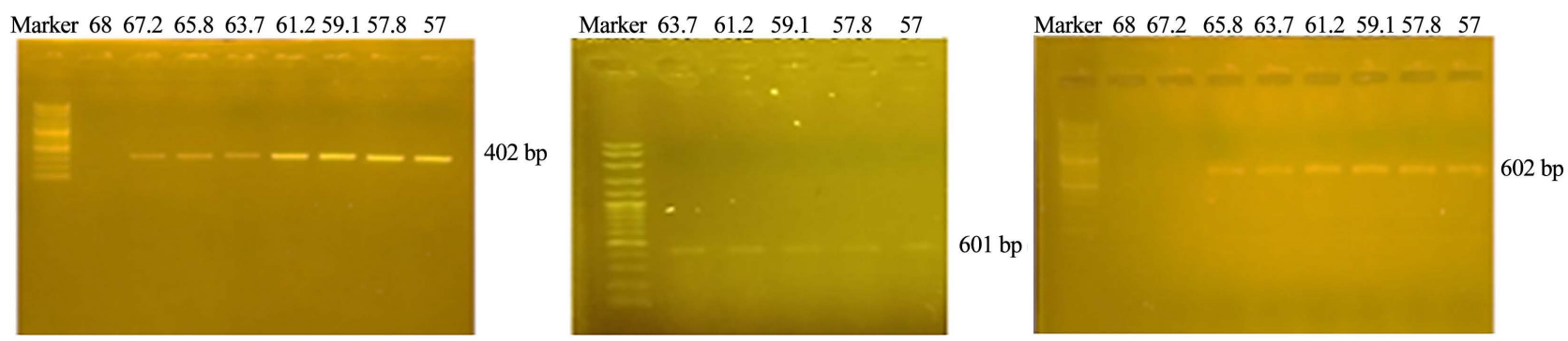

Figure 3. Electrophoresis of Primers PDE5.

template in accordance with the desired results. In addition to the primary factors there are also other factors such as dNTP, PCR templates, number of cycles, polymerase enzymes, and technical and non-technical effects. But primer selection is one way to minimize failure of template DNA amplification. Primers that successfully amplify DNA template is sequence reverse:

TGCATTGACCATGTCTCTCGTT, forward: CGCCGATCTGGGCTGAACTA.

\section{Conflicts of Interest}

The authors declare no conflicts of interest regarding the publication of this paper.

\section{References}

[1] Greco, E.A., Spera, G. and Aversa, A. (2006) Combining Testosterone and PDE5 Inhibitors in Erectile Dysfunction: Basic Rationale and Clinical Evidences. European Urology, 50, 940-947. https://doi.org/10.1016/j.eururo.2006.06.049

[2] Lin, C-S., Lin, G. and Lue, T.F. (2003) Isolation of Two Isoforms of Phosphodiesterase 5 from Rat Penis. International Journal of Impotence Research, 15, 129-136. https://doi.org/10.1038/sj.ijir.3900983

[3] Wright, P.J. (2006) Comparison of Phosphodiesterase Type 5 (PDE5) Inhibitors. International Journal of Clinical Practice, 60, 967-975. https://doi.org/10.1111/j.1742-1241.2006.01049.x

[4] Zhang, X.-H., Morelli, A., Luconi, M., Vignozzi, L., Filippi, S., Marini, M., Barbara, V.G., Mancina, R., Forti, G. and Maggi, M. (2005) Testosterone Regulates PDE5 Expression and in Vivo Responsiveness to Tadalafil in Rat Corpus Cavernosum. Eurepean Urology, 47, 409-416.

[5] Marisa, S.A. (2015) Handling of Erectile Dysfunction Early. Journal of Community and Tropical Medicine, 3, 196-199.

[6] Gratzke, C. (2008) Daily Use of PDE5-Inhibitors: The Road to Happiness. European Urology, 54, 28-30. https://doi.org/10.1016/j.eururo.2008.03.030

[7] Timothy, M., Rose, J.G. and Henikoff, S.H. (2003) CODEHOP (COnsensus-DEgenerate 
Hybrid Oligonucleotide Primer) PCR Primer Design. Nucleic Acids Research, 31, 3763-3766. https://doi.org/10.1093/nar/gkg524

[8] Chen, J., Li, X.Y., Li., X.M. and Chen, D.J. (2017) The Environmental Pollutant BDE-209 Regulates NO/cGMP Signaling through Activation of NMDA Receptors in Neurons. Environmental Science and Pollution Research, 25, 3397-3407. https://doi.org/10.1007/s11356-017-0651-5

[9] Ryu, S.Y., Choi, Y.-J., Park, S.-Y., Kim, J.-Y., Kim, Y.-D. and Kim, Y.-W. (2018) Udenafil, a Phosphodiesterase 5 Inhibitor, Reduces Body Weight in High-Fat-Fed Mice. The World Journal of Men's Health, 36, 41-49. https://doi.org/10.5534/wjmh.17028

[10] Fiore, D., Gianfrilli, D., Silvia, C., Fabio, N., Andrea, L., Andrea, M.I. and Mary, A.V. (2018) Chronic Phosphodiesterase Type 5 Inhibition Has Beneficial Effects on Subcutaneous Adipose Tissue Plasticity in Type 2 Diabetic Mice. Journal of Cellular Physiology, 1, 1-7.

[11] Wu, J.S., Lee, C. and Shiue, Y. (2004) Primer Design Using Genetic Algorithm. Bioinformatics, 20, 1710-1717. https://doi.org/10.1093/bioinformatics/bth147

[12] Demitriadis, F., Koukas, S., Ginnakis, D., Tsounapi, P., Saminis, G., Saito, M., Takenaka, A. and Sofikitis, N. (2012) The Role of PDE5 Inhibitors in the Treatment of Testicular Dysfunction. Male Infertility, 1, 77-106.

[13] Toque, A.H., Priviero, B.M.F., Zemse, M.S., Antunes, E., Teixeira, E.C. and Webb, R.C. (2009) Effect of the Phosphodiesterase 5 Inhibitors Sildenafil, Tadalafil and Vardenafil on Rat Anococcygeus Muscle: Functional and Biochemical Aspects. Clinical and Experimental Pharmacology and Physiology, 36, 358-366. https://doi.org/10.1111/j.1440-1681.2008.05071.x

[14] Bivalacqua, T.J., Sussan, T.E., Gebska, M.A., Strong, T.D., Berkowitz, E., Biswal, S., Burnett, A.L. and Champion, H.C. (2009) Sildenafil Inhibits Superoxide Formation and Prevents Endothelial Dysfunction in a Mouse Model of Secondhand Smoke Induce Erectile Dysfunction. Journal of Urology, 181, 899-906. https://doi.org/10.1016/j.juro.2008.10.062

[15] Wael, S. and Mahulette, F. (2013) The Effect of Administrate of Alkohol (Sopi) on Spermatozoa Rat (Sprague dawley). Bimafika, 4, 495-498.

[16] Dehghani, F., Heshmatpour, A., Panjehshahin, M.R. and Khozani, T.T. (2012) Toxic Effects of Water/Alcoholic Extract of Syzygium aromaticum on Sperm Quality, Sex Hormones and Reproductive Tissues in Male Mouse. IUFS Journal of Biology, 71, 95-102.

[17] Ang, H.H. and Lee, K.L. (2002) Effect of Eurycoma Longifolia Jack on Libido in Middle-Aged Male Rats. Journal of Basic \& Clinical Physiology \& Pharmacology, 13, 249-253. https://doi.org/10.1515/JBCPP.2002.13.3.249

[18] Sumalatha, K., Kuma, A.S. and Lakshmi, S.M. (2010) Review on Natural Aphrodisiac Potentials to Treat Sexual Dysfunction. International Journal of Pharmacy \& Therapeutics, 1, 6-14.

[19] Ang, H.H., Ikeda, S. and Gan, E.K. (2001) Evaluation of the Potency Activity of Aphrodisiac in Eurycoma longifolia Jack. Phytotherapy Research, 15, 435-436. https://doi.org/10.1002/ptr.968

[20] Isidori, A.M., Buvat, J., Corona, G., Goldstein, I., Jannini, E.A., Lenzy, A., Porst, H., Salonia, A., Traish, A.M. and Maggi, M. (2013) A Critical Analysis of the Role of Testosterone in Erectile Function: From Pathophysiology to Treatment-A Systemic Review. European Urology, 65, 99-112.

https://doi.org/10.1016/j.eururo.2013.08.048 
[21] Yakubu, M.T., Akanji, M.A. and Oladiji, A.T. (2005) Aphrodisiac Potentials of the Aquaeous Extract of Fadogia agrestis (Schweinf. Ex Hiern) Stem in Male Albino Rats. Asian Journal of Andrology, 7, 399-404. https://doi.org/10.1111/j.1745-7262.2005.00052.x

[22] Swati, R. and Motwani, S. (2012) A Short Review on Aphrodisiac. International Journal of Research and Development in Pharmacy and Life Sciences, 1, 122-125.

[23] Sing, S., Nair, V. and Gupta, Y.K. (2012) Evaluation of the Aphrodisiac Activity of Tribulus terrestris Linn. in Sexually Sluggish Male Albino Rats. Journal of Pharmacology and Pharmacotherapeutiks, 3, 43-46. https://doi.org/10.4103/0976-500X.92512

[24] Chedrese, P.J. (2009) Introduction to the Moleculer Organization of the Endocrine Reproductive System. In: Reproductive Endocrinology, Springer, New York, 3-10.

[25] Ramachandran, S., Sridhar Y., Sam, S.K.G., Saravanan, M., Leonard, J.T., Anbalagan, N. and Sridar, S.K. (2004) Aprodisiac Activity of Butea frondosa Koen. ex Roxb. Extract in Male Rats. Phytomedicine, 11, 165-168.

https://doi.org/10.1078/0944-7113-00343

[26] Abd-Elsalam, K.A. (2003) Minireview Bioinformatic Tools and Guideline for PCR Primer Design. African Journal of Biotechnology, 2, 91-95.

[27] Dinda, E.K., Sasmito, R.K. and Izzati, M. (2014) Characteristic of Primar on Polymerase Chain Reaction (PCR) for DNA Sequencing: Mini Review. National Seminar on Medical Informatics (SNIMed).

[28] Yang, C.H. and Cheng, Y.H. (2008) Primer Design with Specific PCR Product Size Using Memetic Algorithm. 2008 IEEE Conference on Soft Computing in Industrial Applications, Muroran, Japan, 25-27 June 2008, 332-337.

[29] Cahill, K.B., Quade, J.H., Carleton, K.L. and Cote, R.H. (2012) Identification of Amino Acid Residues Responsible for Theselectivity of Tadalafil Binding to Two Closely Related Phosphodiesterases, PDE5 and PDE6. Biological Chemistry, 287, 41406-41416. https://doi.org/10.1074/jbc.M112.389189

[30] Sanchez, L.S., de la Monte, S.M., Filippov, G., Jones, R.C., Zapol, W.M. and Bloch, K.D. (2017) cGMP-Binding, cGMP-Specific Phosphodiesterase (PDE5) Gene Expression Is Regulated during Rat Pulmonary Development. Biological Chemistry, 627, 41406-41416. 